\title{
Multi Node Based Smart Monitoring System with Motor Dry Run Avoidance for Sustainable Agriculture
}

\author{
Priyanka Kanupuru*, Uma Reddy Nadig Vijayendra Reddy \\ Department of Electronics and Communication Engineering, AMC Engineering College, Affiliated to Visvesvaraya \\ Technological University, Bangalore 560083, India
}

Corresponding Author Email: priyanka.k@vemanait.edu.in

https://doi.org/10.18280/i2m.200106

Received: 11 December 2020

Accepted: 25 February 2021

\section{Keywords:}

agricultural internet of things, intelligent monitoring, wireless monitoring sensor nodes

\begin{abstract}
Food is the major source for the existence of the mankind. In order to meet the food requirements for the ever increasing population, the quantity of the food production has to be increased maintaining the quality standards. Agriculture is one such major sector which provides the food for mankind. It not only provides food but also supplies raw materials for industries. Implementation of advanced technologies such as Internet of Things in agriculture helps in improving the production with limited resources. The key parameter for the sustainable agriculture is moisture content available for the crop from the soil. This can be supplied efficiently by controlling the irrigation process. In this system an intelligent agriculture monitoring system with multiple wireless monitoring sensor nodes are used at different locations to monitor the parameters such as temperature, moisture content in the soil, humidity and rainfall. The data from the various sensors is aggregated at each node and transmitted to the coordinator station using long range transceiver. The data received at the coordinator station is subjected to a rule based decision making process to efficiently control the irrigation process. Also motor protection against the dry run was implemented, which not only protects the motor from break down but also avoids the unwanted power consumption. All the live data is in turn uploaded to the cloud so that the user can have a track of the current status of his farm at any time.
\end{abstract}

\section{INTRODUCTION}

With the ever increasing population, the competition for the resources is increasing, food is one among them. The entire world is indirectly dependent on the agricultural outcome. Sustainability in agriculture is process of employing suitable ways in the field which helps in meeting the ever increasing demand. At the same time modernization in agriculture is also essential. This modernization from the traditional practices, started with the utilization of tractor in the agriculture and this paved the way for industrial agriculture [1]. To meet the challenges, an automation in agriculture with data driven management is essential. This can be achieved with the Internet of Things. Agricultural Internet of things refers to managing the remote sensors, actuators, autonomous vehicles that are deployed in field with the help of internet there by intergrating automation and decision support in one system.

Energy management in agriculture is one of the major issue. Agriculture has also its role in the emission of green house gases. Hence there is a need to schedule or control the usage of energy resources in agriculture [2]. Climatic changes, plantation density, soil pollution due to pesticides [3, 4], air pollution due to road transport vehicles are also impacting the yield in the agriculture. The crops which are closer to roads have greater impact when compared to the faraway fields [5]. There are five major types of risks in the agriculture [6]. 1) production- is affected due to change in environmental parameters, pests, soil minerals, diseases etc. 2) Market risks uncertainty in the prices due to the demand and yield. 3)
Institutional risks - occurs due to unpredictable agriculture related policy changes in government. 4) Personal risk - it is related to the individual. Factors such as health, family issues, income may influence the individual. 5) Financial risk - this refers to financial in flow towards the crop maintenance. It also includes availability of loans and the rate of interest. All these are some of the parameters that influence the agriculture production. In rural areas due to lack of storage and infrastructural facilities, farmers are selling their crop at the point of origin to the middle men. They are in turn unaware for existing market prices, therefore middle men are fetching huge profits [7].

Imparting the digital innovations in agriculture can maximize the yield and also paves the way for sustainable agriculture. This can be done by employing the wireless sensor networks for gathering the field level parameters [8]. Coverage and proper connectivity of the nodes to the base station is also essential [9]. This real time monitoring using wireless sensor networks, generates huge amount of data. Based on the useful extracted data, the farmers can take timely efficient decisions and also controls the irrigation process automatically [10]. The various sensors that are employed in the system are prone to various attacks, because they are deployed in harsh environment [11]. Various communication technologies such as RFID, Wi-Fi, LoRa, LTE, IPv6 Low-power Wireless Personal Area Network, Blue tooth, Zigbee etc., can be used for data transmission in agriculture [12]. Updating the data to cloud in turn helps in adding the intelligence to data to facilitate for further predictive analysis $[13,14]$. 
Usage of zigbee and Blue tooth for data transmission limits the distance between the wireless sensor nodes and central station. For data transmission over longer distances multi hop communication can be used, but the disadvantage is the increased forwarding time and additional hardware requirement for multiple hops. In this system $\mathrm{HC12}$ transceiver is used to overcome this problem, and helps in data transmission over longer range.

\section{RELATED WORK}

Researchers had developed many models relating to smart monitoring of agricultural parameters to improve the productivity and sustainability. Ayyasamy et al. [15], proposed an excess water removal system. The excess water in agricultural land occurs due to various reasons such as rain, improper irrigation scheduling, floods etc. Removing the excess water from the agricultural land prevents the rotten of the plant root. Maintaining the soil $\mathrm{pH}$ helps in preserving various micronutrients such as zinc, manganese, iron, etc., salinity sensor based on BC548 transistor, can be used to indicate the presence of salt water. Employing solar energy in the agriculture helps in the effective utilization of the resources [16]. Shi et al. [17], defined a Plant water deficit index (PWDI), which gives the information about the capability of the plant roots in absorbing the water content from soil. This parameter was analyzed by measuring the root profile.

Nagarajal et al. [18] proposed a smart system for monitoring using raspberry pi, the various parameters that are monitored on the farm land are stored in fire base. This data is inturn used for the crop prediction by processing through machine learning algorithms. Kadar et al. [19] developed an AGRI2L system. In this the water leakage from the PVC pipes are detected by analyzing the data from flow rate sensor and water level sensor. The status was intimated to farmer using mobile app. Doshi et al. [20] proposed an automated farm monitoring process by using various sensors and calculated power consumption per hour in sleep mode, active mode. switching to sleep mode helps in extending the life of power bank.

Kumbhar et al. [21] proposed an agriculture 3-phase induction motor protection system by using R, Y, B voltage sensors and vibration sensors. This system gives an alert message using GSM during voltage variations. Bulusu et al. [22], proposed a detection mechanism for phase imbalance fault condition and phase loss condition for the agricultural motor by developing a voltage and current measurement unit. The motor is made to trip under the imbalance condition with the help of arduino and opto-coupler with relay. Ulaganathan et al. [23] proposed a motor protection system by identifying the current overload and phase absence condition. It also intimates the farmer using GSM module. Balakrishna et al. [24] developed a motor status tracking and inturn controlling system raspberry pi module to identify the conditions like motor malfunction, no power and no ground water. Android application was developed to update these conditions to farmer. Suleman et al. [25] developed a multi node monitoring system consisting of sensors are equipped with arduino uno, to collect the micro nutrients such as nitrogen, and potassium and soil moisture content from the soil. This data is sent to the master station using xbee module to control the irrigation. Prakash Jadhav et al. [26] used mesh topology for connecting the multiple nodes and coordinator for intelligent monitoring in agriculture.

Most of the work is based on the analysis of the agricultural parameters at a single node and updating the data to user with the help of Internet of things. In case if the node fails the entire system becomes idle. By considering the multiple nodes an enhancement in the decision making approach can be realized. Under some situations, the flow sensor may give false readings to identify motor dry run because of the air drawn by the motor.

\section{PROPOSED SYSTEM FRAME WORK}

The implementation frame work is categorized into three parts 1) Wireless monitoring sensor nodes, 2) coordinator station and 3) data logger.

\subsection{Wireless monitoring sensor nodes}

In the case of large farms, the data analysis using a single node may not give the accurate results. Deploying multiple nodes improves the precision in decision making process. The wireless monitoring sensor nodes are deployed at various locations in the field to capture the agri - environment data. In this proposed system, three nodes are deployed at three distinct locations in the field. To conveniently identify the nodes, three sensing nodes are named as node 1 , node 2 and node 3 . All these are stationary nodes, their position in the field is fixed. All the nodes are powered using the external $6000 \mathrm{mAh}$ power bank. Each node consists of a sensing module, microcontroller and a transmitter. The sensing module includes multiple sensors such as DHT11 -temperature and humidity sensor, soil moisture sensor and rain detector. Arduino uno microcontroller is used to gather the data from sensing modules at regular intervals of time. Further this data is transmitted to the coordinator station using $\mathrm{HC} 12$ radio frequency $(\mathrm{RF})$ transceiver. The same setup is used for all the three nodes.

\subsubsection{Temperature and humidity sensor}

The DHT 11 sensor measures the temperature and relative humidityin itssurroundings. The temperature is measured based on the negative temperature coefficient of the thermistor. As the temperature of the surroundings increases the resistance decreases. The relative humidity is measured using the capacitive sensing element. Change in relative humidity results in the change in the capacitance values. The data frame sent by the sensor consists of humidity followed by the temperature.

\subsubsection{Soil moisture sensor}

The FC-28 sensor consisting of two probes acts as a variable resistor. When the sensor is inserted into the soil, it measures the volumetric water content present in the soil as a function of content of the water in the soil. During the presence of moisture in the soil, the resistance decreases and the conductivity increases [27]. The module outputs the voltage in accordance with the resistance.

\subsubsection{Rain sensor}

The FC-37 rain sensor is used to sense the presence of rain. The module consists of a control board and a rain or collector board. The copper tracks are present on the collector board. Under no rain condition, because of dryness the on the board, resistance is high and the control board produces an output 
value 1023. During the presence of rain, the output value reduces from 1023 to 0 , in accordance with the reduced value of the resistance.

\subsubsection{HC12RF Transceiver}

It is a serial communication module with multiple channels and capable of transmitting the data in wireless manner over a range nearing to about $1 \mathrm{Km}$ in the open environment. It consists of 8 bit STM8S003F3 microcontroller and Si4463 transceiver. It supports multiple baud rates with FU1, FU2 and FU3 transmission modes with FU3 being the full speed mode. The module comes with the default setting of baud rate 9600bps, FU3 mode, (8-bit data and one stop bit), CH001 $(433.4 \mathrm{MHz})$. The parameters can be varied with the help of AT commands. The default settings itself were used in this system for data transmitting the data from each of the nodes to coordinator.

\subsection{Coordinator station}

The coordinator station consisting of arduino uno, collects the data from the nodes 1, 2, and 3 with the help of the HC12 transceiver. The transceiver is connected to the serial port of arduino uno receives the data in wireless manner. The irrigation motor supplies the water to the field and dewaterting motor removes the excess water, accumulated during heavy rains. The received data is analyzed by the microcontroller and the actuation of the irrigation motor and dewatering motor occurs accordingly. Both the motors are connected to the coordinator station through relays. The current sensor is connected in series with the irrigation motor measures the current flowing through the motor. The ATmega328P microcontroller is also interfaced with LCD to display the node failure status and Buzzer to alert the farmer in the case of irrigation motor dry run.

\subsection{Data logger}

The ESP8266 acts as the data logger. It receives the soil moisture and rain sensor data of all the nodes 1,2 and 3, the current sensor data, status of the irrigation motor and dewatering motor from the coordinator station in the scheduled intervals of time. The received data is in turn uploaded to thing speak cloud. It is an open source cloud application to send and receive the data. The data is uploaded to cloud using the hyper text transfer protocol (HTTP) protocol over the Internet.

\section{SYSTEM IMPLEMENTATION}

Multi node, multi sensor smart monitoring system gathers the agri-environment parameters from distinct locations. The sensor connection diagram of one node is shown in the Figure 1 below was drawn using fritzing.

Wireless monitoring node interconnection diagram remains same for all the sensing nodes 1,2 and 3. Aurdino uno is the heart of each of these sensing nodes. For each node, DHT11, soil moisture sensor, rain detector are connected to the arduino uno analog pins. The microcontroller reads the data from these sensors at regular intervals of time. The data is transmitted from the node to the central station using the HC12 RF transceivers. Each of the nodes transmits the sensor data along with the node header with a baud rate of 9600 . Each node has a unique header, the respective node number is specified in the header portion. Therefore the receiver can clearly distinguish the received data, by analyzing the header whether it is belonging to node 1,2 or 3 . The nodes and coordinator station connectivity diagram is shown in the Figure 2.

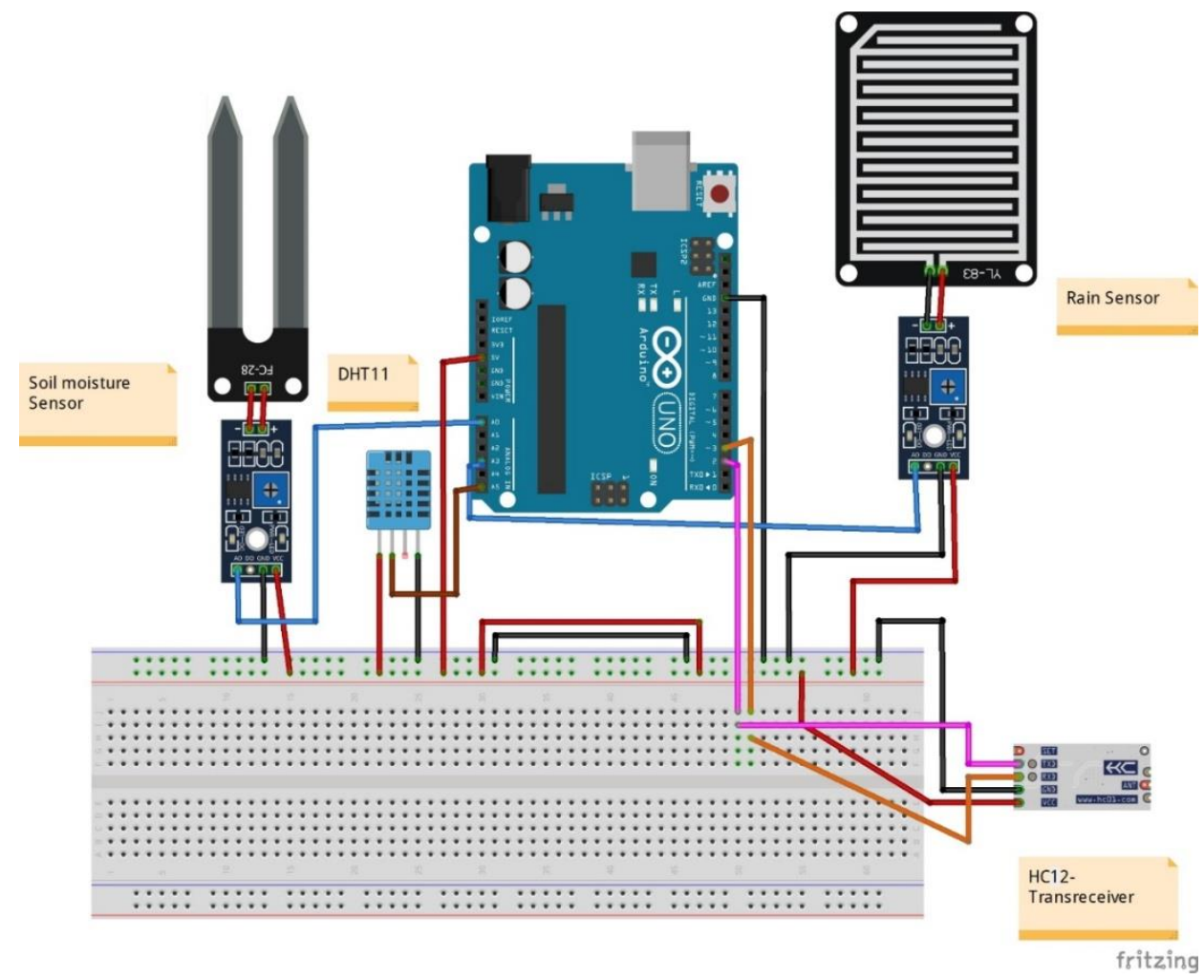

Figure 1. Interconnection diagram of a node 


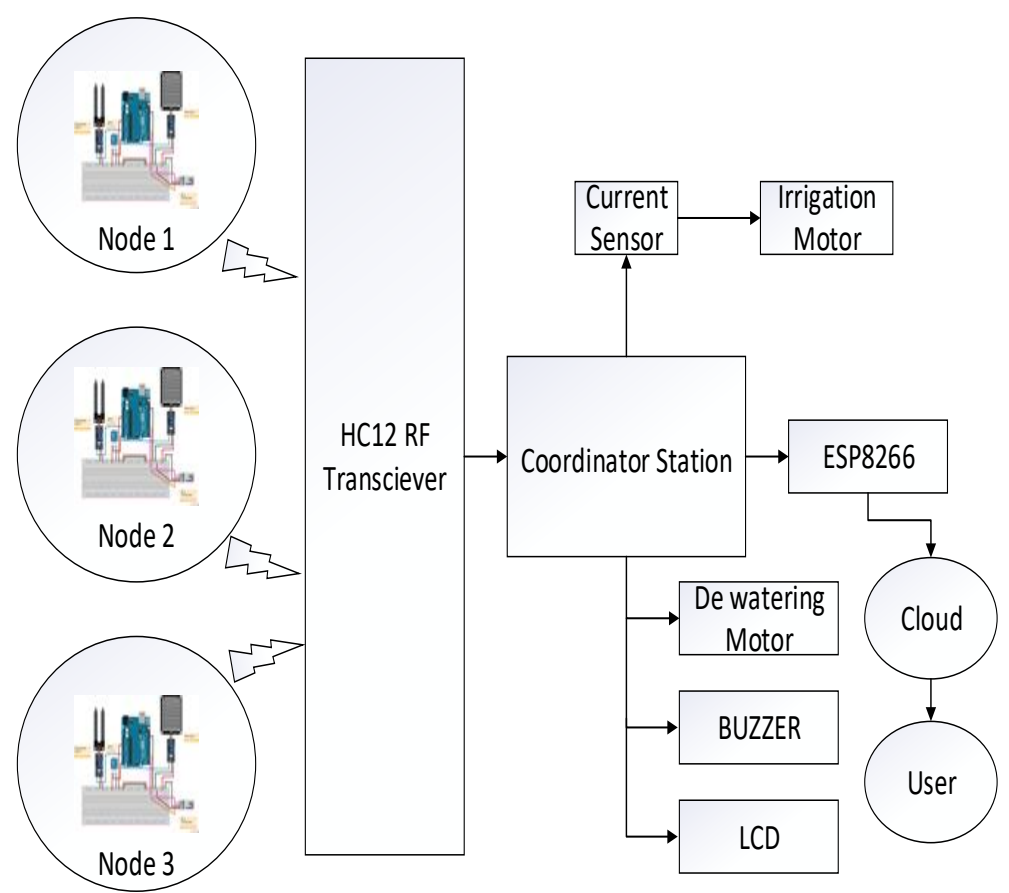

Figure 2. Block diagram of a coordinator station
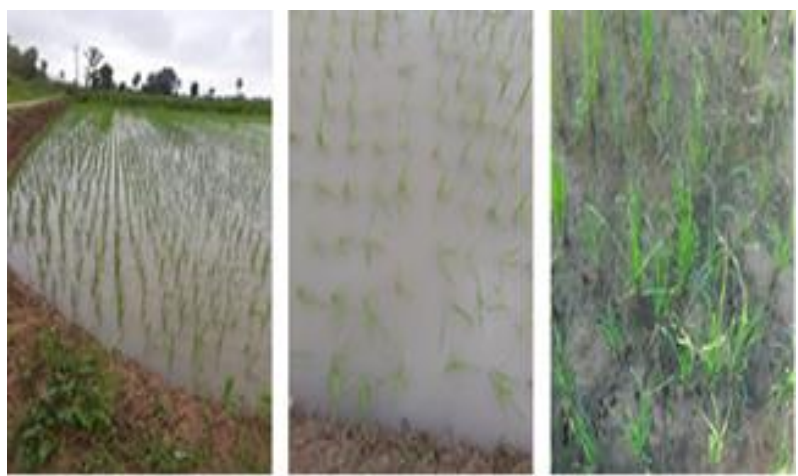

(a) Heavy rain; (b) Heavyrain; (c) Mild rain

Figure 3. Images of different water levels accumulated in paddy field

All the nodes and the coordinator station are connected wirelessly in the form of star topology. The central station is also equipped with HC 12 RF transceiver, which now acts as a receiver and collects the data from the three nodes. The individual agricultural parameters are extracted from received data and are analysed for actuating the motors. Under the presence of predominant rain, excess water gets accumulated into the field. In the following Figure 3 (a), (b) shows such situation of the paddy crop drowned in the water due to heavy rain. Condition of the crop under mild rain is shown in the Figure 3(c).

These images are captured in the paddy field after heavy rain in the region of Andhra Pradesh, India, in the month of november 2020.

If the necessary action was not taken to remove the excess water out the crop area, the roots become weak and it may even leads to the death of the plants due to the prolonged stay in the water. It results a huge loss to farmers. Therefore the dewatering motor helps to remove the excess water out of the fields. Mild rain situation is tolerable as the land takes less time to dry when compared to heavy rain.

By analyzing the soil moisture and rain sensor data, the irrigation motor and dewatering motor actuation is controlled by the microcontroller at coordinator station. The various cases and the action taken are shown in the Table 1 below.

The mapping of the rain and soil sensor analog data to digital data is given by Eq. (1).

$$
\text { Digital Value }=\frac{\text { Signal value }}{5} * 1023
$$

The system contains 10 bit analog to digital converter (ADC). The soil and rain threshold values are set according to the mapped reading. The functioning of the central station under various conditions is explained in the Figure 4.

Table 1. Action taken at coordinator station under various cases

\begin{tabular}{|c|c|c|c|}
\hline Cases & Parameter analyzed & Decision & Action taken \\
\hline $\begin{array}{c}\text { Case } \\
1\end{array}$ & $\begin{array}{l}\text { Atleast one soil moisture sensor indicates soil dry and no rain status } \\
\text { from all three rain sensors }\end{array}$ & No Rain, Soil- Dry & $\begin{array}{c}\text { Motor 1- } \\
\text { Irrigation motor On, Motor } 2 \text { - } \\
\text { Dewatering motor off. }\end{array}$ \\
\hline $\begin{array}{l}\text { Case } \\
2\end{array}$ & $\begin{array}{l}\text { All the soil sensors indicate soil wet and rain sensors indicate the } \\
\text { presence of predominant rain fall }\end{array}$ & Predominant rain and soil Wet & $\begin{array}{c}\text { Motor 1 - } \\
\text { Irrigation motor Off, Motor 2- } \\
\text { Dewatering motor on. }\end{array}$ \\
\hline $\begin{array}{c}\text { Case } \\
3\end{array}$ & $\begin{array}{l}\text { All the soil sensor indicate the soil is wet and presence of mild rain/ } \\
\text { no rain }\end{array}$ & Mild rain/ no rain and Soil wet & $\begin{array}{l}\text { Motor } 1 \text { - Irrigation motor off, } \\
\text { Motor } 2 \text { - Dewatering motor off. }\end{array}$ \\
\hline
\end{tabular}




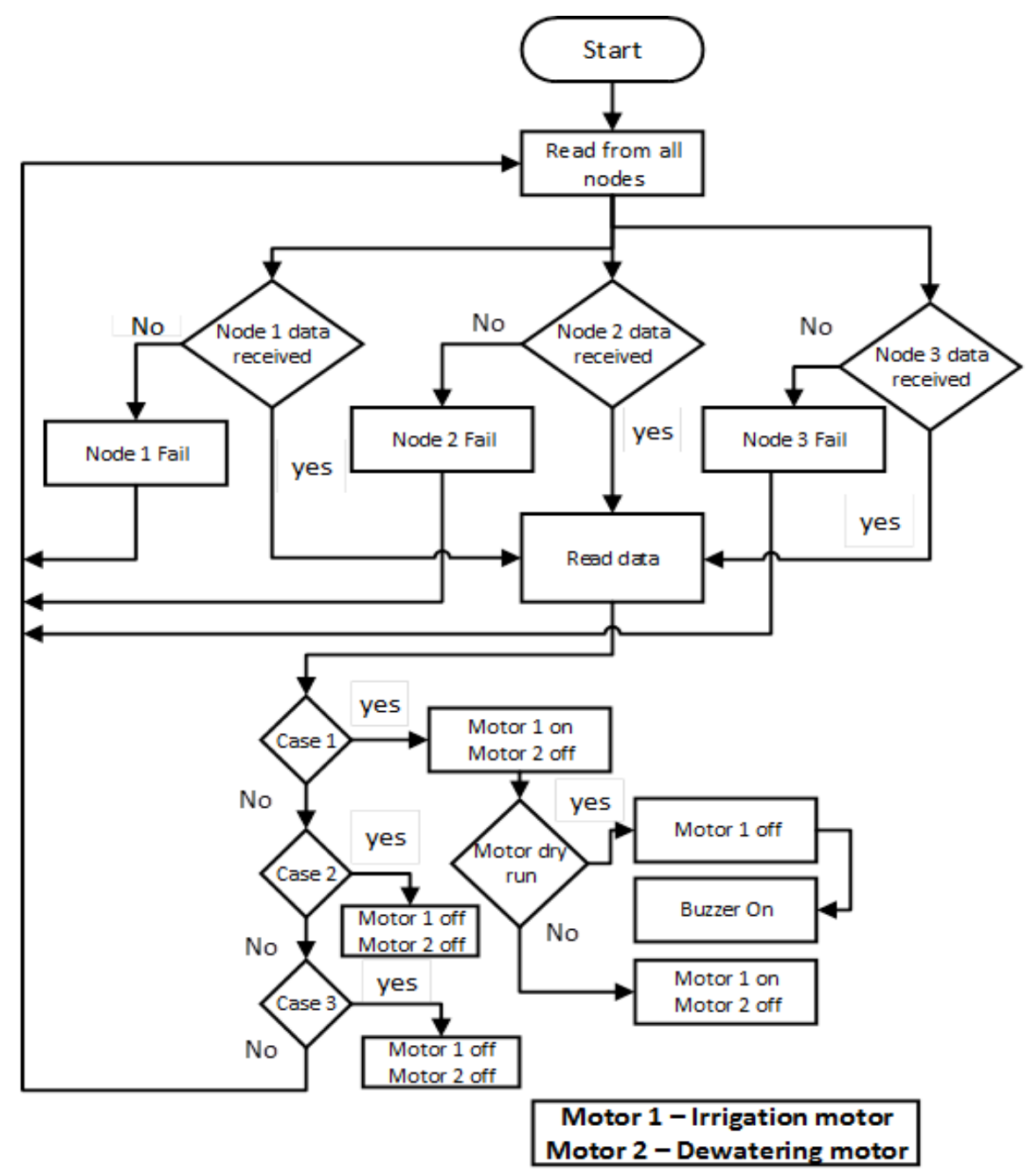

Figure 4. Flow chart indicating the control process carried out at coordinator station

When soil and rain moisture sensor data are greater than the soil threshold and rain threshold, it indicates that the soil is dry and no rain. Therefore the irrigation motor is switched on. The irrigation motor draws the water from the water source and supplies to the field. Under this condition if the water source is dry or the level of the water is too low for the motor to extract, the motor fails to pump the water and its runs continuously with no water. This condition was termed as motor dry run. In long run it may even damage the motor, further the power consumed by the motor leads to wastage of resources. To avoid this condition, a current sensor ACS712 was connected in series with the irrigation motor. When the motor has the sufficient amount of water at its source point it draws more current, to pump the water, when compared to no water at the source point. Based on this data from the current sensor, the microcontroller controls the switching of irrigation motor. When the current senor reading is below the threshold value, immediately the irrigation motor is turned off and buzzer is turned on to alert the farmer. Therefore the dry run condition is avoided, which not only protects the motor but also saves power.

In case no data is received from any particular node for a predominant amount of time due to power failure then that particular node was treated as malfunctioned and the status of the same is indicated through the LCD present in the central station as shown in Figure 5, as node fail 1 or node fail 2 or node fail 3 depending the failed node. Therefore the farmer can take necessary measures to make the node operational.

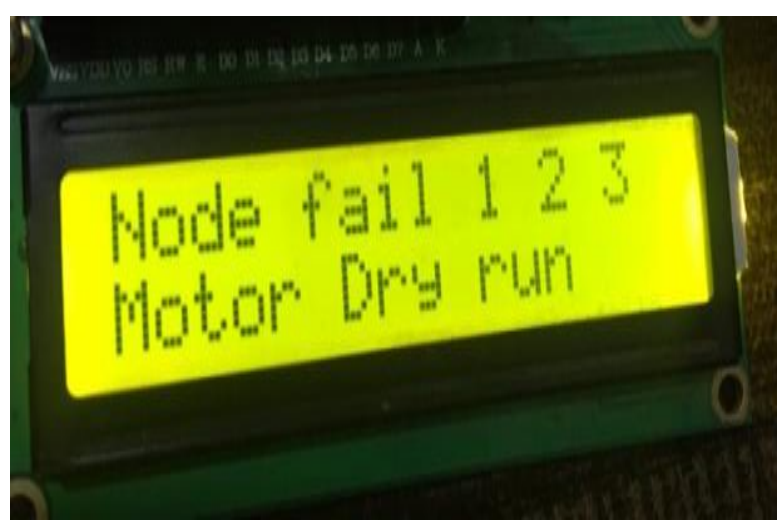

Figure 5. Node status on LCD

\section{RESULTS AND DISCUSSIONS}

In this system, single phase, 0.5 Horsepower, 200-240 volts motor was used as an irrigation motor.By analyzing the received data from the three nodes as mentioned in the flowchart, the coordinator station actuates the irrigation motor or the dewatering motor. Before connecting the irrigation motor to central station, the $\mathrm{m}$ number of current readings under the presence of water was noted as $\mathrm{w}_{\mathrm{i}}$, where $\mathrm{i}=$ $1,2,3, \ldots \mathrm{m}$. Similarly the $\mathrm{p}$ number of recoded readings under dry run was noted as $n w_{j}$, wherej $=1,2,3, \ldots$. 


$$
\begin{gathered}
\text { Motor }_{\text {water }}=\frac{1}{m} \sum_{i=1}^{m} w_{i} \\
\text { Motor }_{\text {nowater }}=\frac{1}{p} \sum_{j=1}^{p} n w_{j} \\
T=\frac{\text { Motor }_{\text {water }}+\text { Motor }_{\text {nowater }}}{2}
\end{gathered}
$$

Any value between $\mathrm{T}$ and Motor $_{\text {nowater, }}$ can be used as a threshold value to turn off the irrigation motor under dry run condition. The recorded values are shown in the Figure 6.

The readings in the graph, before and after 11:14 indicates, motor running under the presence and absence of water at the source point. The threshold value $\mathrm{T}$ was calculated using Eq. (4). The experimental set up of the multi-node system is shown in Figure 7.

The ADC readings of soil and rain sensor are tabulated in the columns from 1 to 6 of Table 2 .

The variation of soil moisture content from wet to dry are indicated by the values from 0 to 1023 . The rain sensor readings from 0 to 1023 are generated in accordance with predominant rain to no rain.

The multi node data received at the central station are uploaded to the Thing speak cloud using the Esp8266 connected to the coordinator station. The soil and rain data from the nodes along with the motor status of the irrigation motor and dewatering motor are uploaded to the cloud is shown in the Figure 8.

The soil and rain sensor data recorded from the nodes 1,2 and 3 under various conditions as described in the flow chart are visualized in the graphs from Figure 8 (a) to (e). The field 6 illustrates the current sensor data at the coordinator station. Fields 7 and 8 illustrates the on and off status of irrigation motor, dewatering motor in accordance with the cases mentioned in the Table 1.

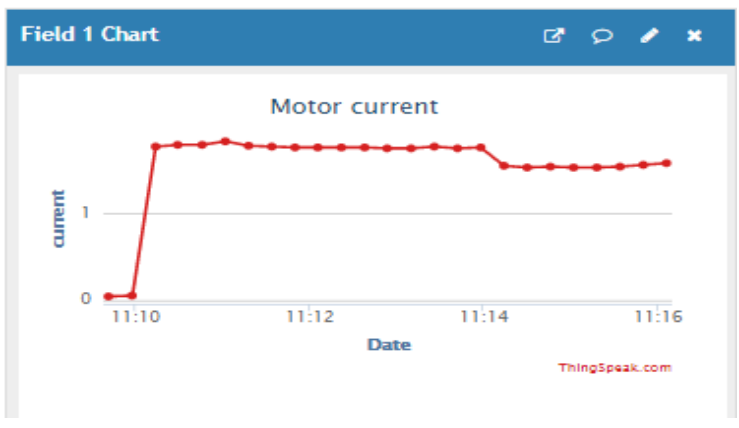

Figure 6. Motor current reading under the presence of water and no water conditions

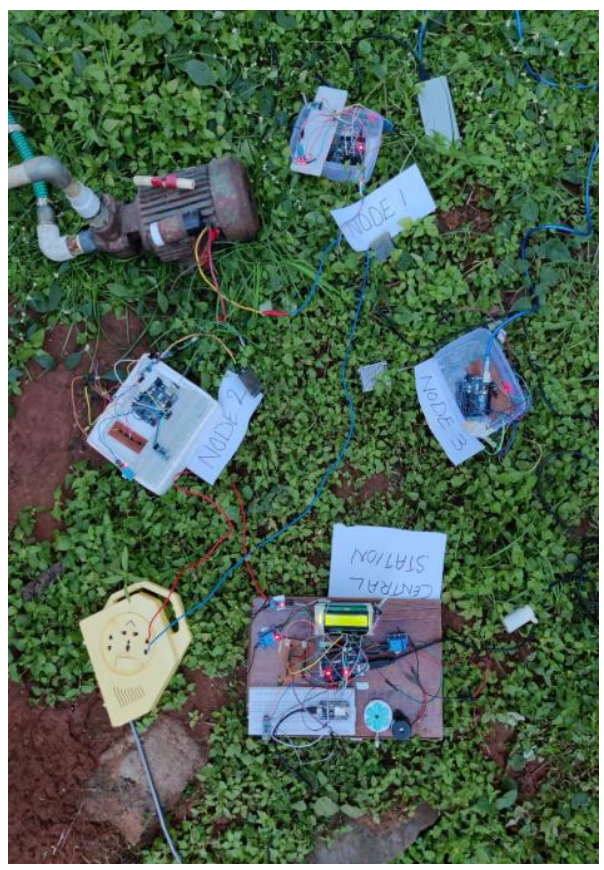

Figure 7. Multi node system set up

Table 2. Multi node sensor readings

\begin{tabular}{llllllllll}
\hline Soil1Soil2Soil3Rain1Rain2 & \multicolumn{7}{l}{ Rain3Current (mA) } & \multicolumn{5}{l}{ Decision taken Irrigation Motor statusDewatering Motor Status } \\
\hline 1023 & 1020 & 1001 & 1020 & 1023 & 1020 & 1.72 & No Rain, Soil- Dry & on & off \\
1020 & 1000 & 950 & 1023 & 1020 & 1000 & 1.72 & No Rain, Soil- Dry & on & off \\
950 & 1020 & 980 & 1023 & 1020 & 1000 & 1.72 & No Rain, Soil- Dry & on & off \\
1020 & 1000 & 950 & 1023 & 1020 & 1000 & 1.72 & No Rain, Soil- Dry & on & off \\
1020 & 1000 & 950 & 1023 & 1020 & 1000 & 1.45 & Motor dry run & off & off \\
980 & 972 & 950 & 1023 & 1023 & 1020 & 1.43 & Motor dry run & off & off \\
300 & 450 & 420 & 552 & 550 & 520 & 0 & Mild rain, Soil wet & off & off \\
320 & 440 & 410 & 500 & 530 & 520 & 0 & Mild rain, Soil wet & off & off \\
280 & 300 & 350 & 250 & 260 & 220 & 0 & Predominant rain & off & on \\
260 & 280 & 300 & 250 & 260 & 220 & 0 & Predominant rain & off & on \\
270 & 280 & 280 & 240 & 250 & 220 & 0 & Predominant rain & off & on \\
\hline
\end{tabular}

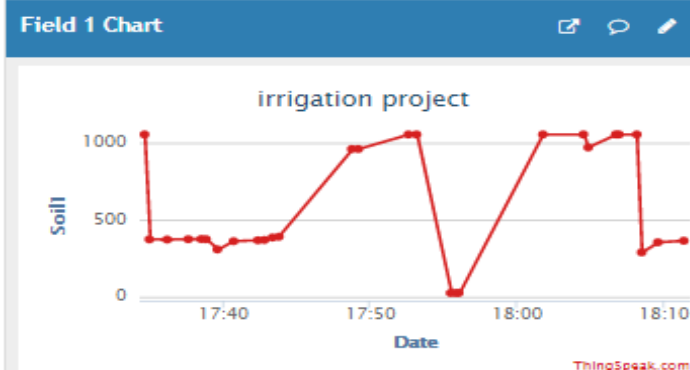

(a) Node1 soil sensor

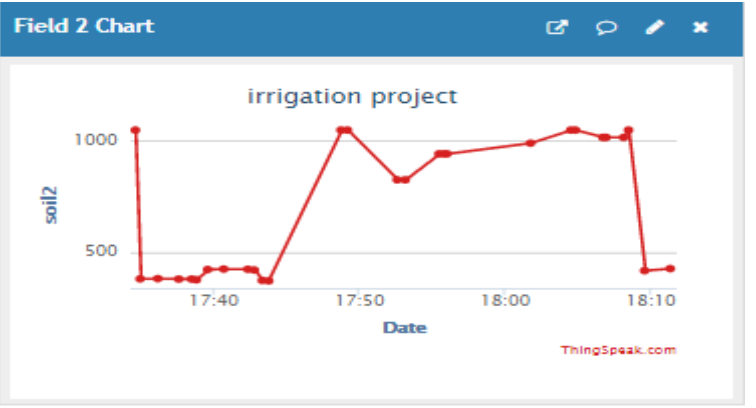

(b) Node2 soil sensor 


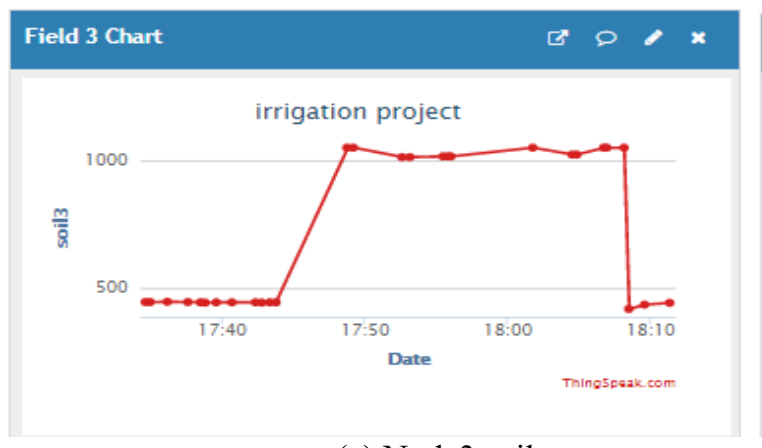

(c) Node3 soil sensor

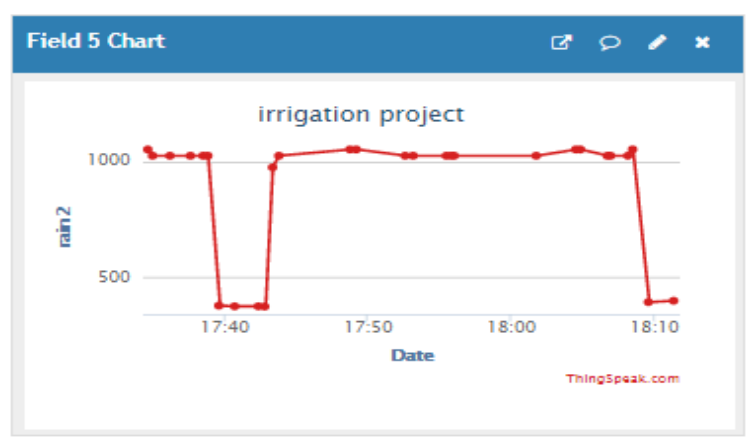

(e) Node2 rain sensor

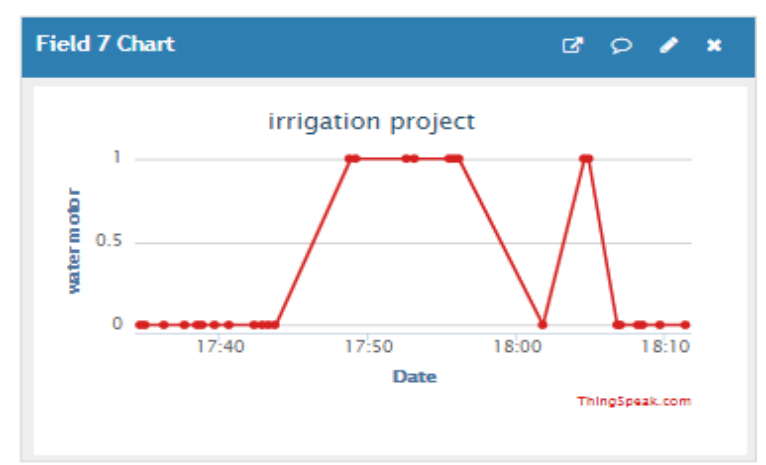

(g) On and off status of irrigation motor

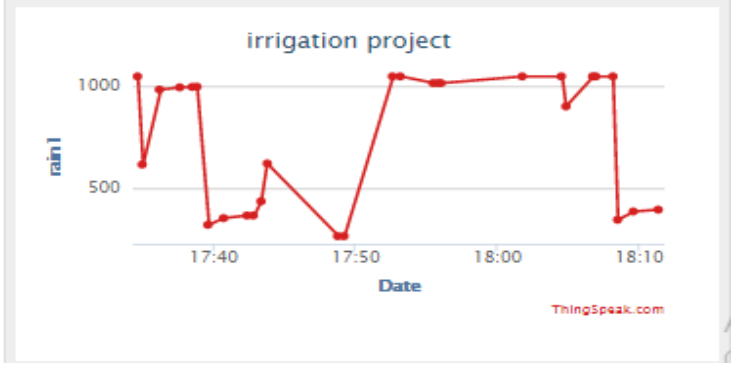

(d) Node1 rain sensor

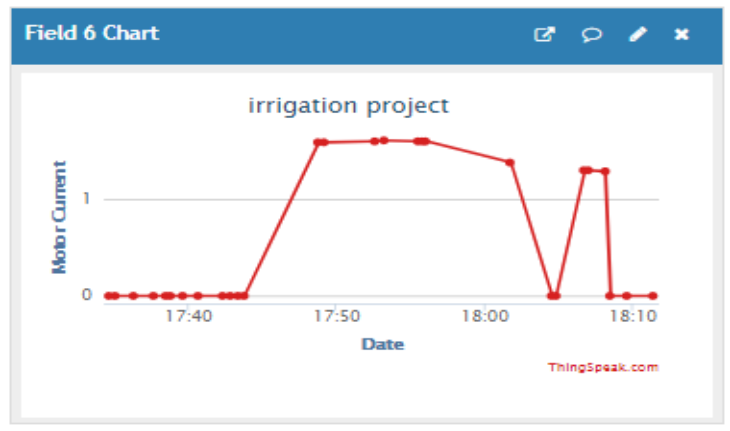

(f) Irrigation motor current

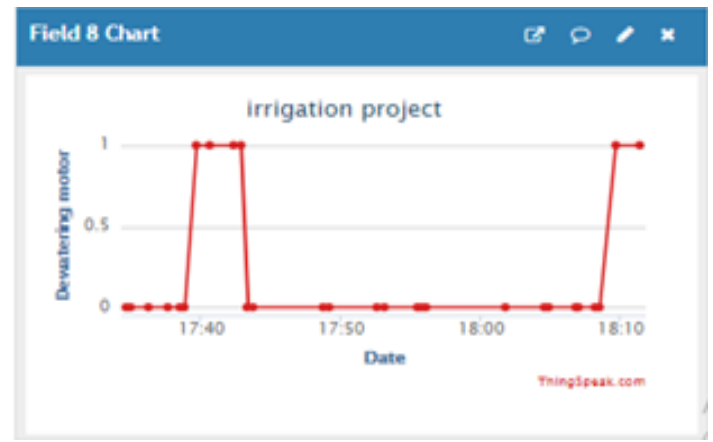

(h) On and off status of dewatering motor

Figure 8. Recorded data on web server

The fall in the current reading from the maximum value in the field chart $8(\mathrm{f})$ indicates the motor is running dry and during that instant of time, field chart $8(\mathrm{~g})$ shows that the irrigation motor was turned off. The same data will be visualized on the users mobile screen with the help of thing speak mobile application. The data uploaded to cloud by the coordinator station can be imported in the form of csv file, which can be used in future for crop prediction analysis.

\section{CONCLUSIONS}

Multi sensor node based precision farming assists in sustainable crop management with effective utilization of water. Analyzing the data from the multiple nodes helps in precise decision making in scheduling the irrigation. Major focus of this research also lies in predicting the availability of water at the motor inlet by measuring the current consumed by the motor. Monitoring the irrigation motor for the dry run condition, not only protects the motor but also saves the time and money for the farmer. The stagnant water, due to heavy rains is pumped out of the crop using dewatering motor. This saves the crop from prolonged stay in excess water. In the proposed system data from the senor nodes to the central station is transmitted using RF transceiver. Therefore the internet connectivity for the entire crop area is not necessary. The internet connectivity at the central station alone is essential to upload the synchronized parameters from the nodes and status of the two motors to the cloud. So that the farmer can monitor the status of the crop from any location in the world.

\section{REFERENCES}

[1] Charania, I., Li, X.R. (2019). Smart farming: Agriculture's shift from a labor intensive to technology native industry. Internet of Things Review Article, 9: 120. https://doi.org/10.1016/j.iot.2019.100142

[2] Abrishambaf, O., Faria, P., Vale, Z. (2019). Energy resource scheduling in an agriculture system using a decision tree approach. IEEE, International Conference on Intelligent System Application to Power Systems (ISAP), New Delhi, India, pp. 1-5. https://doi.org/10.1109/ISAP48318.2019.9065983

[3] Lin, J., Pan, J.L. (2020). Farmers' willingness as well as 
its compensation strategy to prevent and control agricultural non-point source pollution in water source areas-based on a comparative analysis of pesticide and fertilizer inputs. International Journal of Sustainable Development and Planning, 15(8): 1303-1311. https://doi.org/10.18280/ijsdp.150817

[4] Widiati, W., Mulyadi, A., Syahza, A., Mubarak. (2020). Analysis of plantation management achievement based on sustainable development. International Journal of Sustainable Development and Planning, 15(4): 575-584. https://doi.org/10.18280/ijsdp.150418

[5] Affrin, K., Reshma, P., Kumar, G.N. (2017). Monitoring effect of air pollution on agriculture using WSNs. International Conference on Technological Innovations in ICT For Agriculture and Rural Development (TIAR), 46-50. https://doi.org/10.1109/TIAR.2017.8273684

[6] Komarek, A.M., De Pinto, A., Smith, V.H. (2019). A review of types of risks in agriculture: What we know and what we need to know. Article on Agricultural Systems, 178:

$1-10$. https://doi.org/10.1016/j.agsy.2019.102738

[7] Vennila, A. (2018). Current trend of agricultural productivity in India and its future prospects - a review article. International Journal of Engineering Development and Research (IJEDR), 6(3): 46-49.

[8] Garcia, L., Parra, L., Jimenez, J.M., Lloret, J., Lorenz, P. (2020). IoT-based smart irrigation systems: An overview on the recent trends on sensors and IoT systems for irrigation in precision agriculture. Senosrs Journal, 20(4): 1042. https://doi.org/10.3390/s20041042

[9] Shrivastav, K., Kulat, K.D. (2019). Effect of the position of base station in square fields. International Journal of Sustainable Agricultural Management and Informatics, 5(4): $230-248$ https://doi.org/10.1504/IJSAMI.2019.104627

[10] Muangprathub, J., Boonnam, N., Kajornkasirat, S., Lekbangpong, N., Wanichsombat, A., Nillaor, P. (2019). IoT and agriculture data analysis for smart farm. Computers and Electronics in Agriculture, 156: 467-474. https://doi.org/10.1016/j.compag.2018.12.011

[11] Mahbub, M. (2020). A smart farming concept based on smart embedded electronics, internet of things and wireless sensor network. Journal of Internet of Things, 9: 100161. https://doi.org/10.1016/j.iot.2020.100161

[12] Khanna, A., Kaur, S. (2019). Evolution of Internet of Things (IoT) and its significant impact in the field of Precision Agriculture. Computers and Electronics in Agriculture, $157:$

$218-231$ https://doi.org/10.1016/j.compag.2018.12.039

[13] Araby, A.A., Elhameed, M.M.A., Magdy, N.M., Said, L.A., Abdelaal, N., Allah, Y.T.A., Darweesh, M.S., Fahim, M.A., Mostafa, H. (2019). Smart IoT monitoring system for agriculture with predictive Analysis. IEEE, 8th International Conference on Modern Circuits and Systems Technologies (MOCAST), pp. 1-4. https://doi.org/10.1109/MOCAST.2019.8741794

[14] Naresh, M., Munaswamy, P. (2019). Smart Agriculture System using IoT Technology. International Journal of Recent Technology and Engineering (IJRTE), 7(5): 98102. http://dx.doi.org/10.35940/ijrte.2277-3878

[15] Ayyasamy, S., Eswaran, S., Manikandan, B., Solomon, S.P., Kumar, S.N. (2020). IoT based Agri soil maintenance through micro-nutrients and protection of crops from excess water. Fourth International
Conference on Computing Methodologies and Communication (ICCMC 2020), pp. 404-409. https://doi.org/10.1109/ICCMC48092.2020.ICCMC00076

[16] Islam, M.S., Dey, G.K. (2019). Precision agriculture: Renewable energy based smart crop field monitoring and management system using WSN via IoT. International Conference on Sustainable Technologies for Industry 4.0 (STI), Dhaka, Bangladesh, pp. 1-6. https://doi.org/10.1109/STI47673.2019.9068017

[17] Shi, J.C., Wu, X., Wang, X.Y., Zhang, M., Han, L., Zhang, W.J., Liu, W., Zuo, Q., Wu, X.G., Zhang, H.F., Ben-Gal, A. (2020). Determining threshold values for root-soil water weighted plant water deficit index based smart irrigation. Journal of Agricultural Water Management, 230: 105979. https://doi.org/10.1016/j.agwat.2019.105979

[18] Nagaraja, G.S., Soppimath, A.B., Soumya, T., Abhinith, A. (2019). IoT based smart agriculture management system. IEEE 4th International Conference on Computational Systems and Information Technology for Sustainable Solution (CSITSS), pp. 1-5. https://doi.org/10.1109/CSITSS47250.2019.9031025

[19] Kadar, H.H., Sameon, S.S., Rafee, P.A.A. (2019). Sustainable water resource management using IOT solution for agriculture. 9th IEEE International Conference on Control System, Computing and Engineering (ICCSCE), Penang, Malaysia, pp. 121-125. https://doi.org/10.1109/ICCSCE47578.2019.9068592

[20] Doshi, J., Patel, T., Bharti, S.K. (2019). Smart farming using IoT, a solution for optimally monitoring farming conditions. 3rd International workshop on Recent advances on Internet of Things: Technology and Application Approaches (IoT-T\&A), 160: 746-751. https://doi.org/10.1016/j.procs.2019.11.016

[21] Kumbhar, P.P., Mote, P.B., Tate, S.H., Kerutagi, D. (2018). Agriculture (3 Phase $\mathrm{Im}$ ) motor protection and auto alert system using Gsm system. International Journal of Innovations in Engineering Research and Technology (IJIERT), 5(4): 97-100.

[22] Bulusu, S., Sabhanayagan, M., Kumar, J.T., Singh, R.K., Devaraj, D. (2019). Microcontroller based protection relay for agricultural motor. International Journal of Advanced Research in Electrical, Electronics and Instrumentation Engineering, 8(3): 865-873. https://doi.org/10.15662/IJAREEIE.2019.0803046

[23] Ulaganathan, G., AzhaPeriasamy, E.M. (2014). Embedded system based submersible motor control for agricultural irrigation using GSM and to prevent it against over loading, dry running and single phasing automatically. International Journal for Scientific Research \& Development, 2(7): 454-456.

[24] Balakrishna, J., Marellapudi, H., Manga, N.A. (2019). IoT based status tracking and controlling of motor in agricultural farms. 5th IEEE Uttar Pradesh Section International Conference on Electrical, Electronics and Computer Engineering (UPCON), pp. 1-5. https://doi.org/10.1109/UPCON.2018.8596944

[25] Suleman, Y., Manurung, R.V., Kurniawan, D., Hermida, I.D.P., Heryana, A. (2018). Development of precision farming using modular multi node sensor. IEEE, International Conference on radar, Antenna, Microwave, Electronics, and Telecommunications, Serpong, Indonesia, pp. 99-103. 
https://doi.org/10.1109/ICRAMET.2018.8683934

[26] Jadhav, P., Rima, Anjum, S., Pushpalatha, P.H., Shree, N.Y. (2020). Wireless sensor networks for data acquisition and remote actuation. International Journal of Research in Engineering, Science and Management, 3(5): 960-964. http://dx.doi.org/10.47607/ijresm

[27] Bhatnagar, V., Chandra, R., Prasad, J. (2019). Soil moisture sensors for sustainable irrigation: comparison and calibration. International Journal of Sustainable Agricultural Management and Informatics, 5(1): 25-36. https://doi.org/10.1504/IJSAMI.2019.101375

\section{NOMENCLATURE}

$\mathrm{T}$

Motor $_{\text {water }}$

$\mathrm{m}$

Motor $_{\text {nowater }}$

$\mathrm{p}$
Threshold for motor current Mean value of the current under the presence of water at the source point.

Current readings count under the presence of water at the source point.

Mean value of the current in the absence of water at the source point.

Current readings count under the absence of water at the source point. 